\title{
JÁ QUE A HISTÓRIA SE REPETIA COM DIFERENÇAS: O AMADURECIMENTO DE TELÊMACO E MILLY BLOOM
}

\author{
Kelly Lima ${ }^{*}$ \\ Universidade Estácio de Sá
}

\begin{abstract}
Resumo: Entre as diversas referências e os múltiplos paralelos entre o Ulysses de James Joyce e a Odisseia de Homero, destaca-se o espelhamento entre Leopold Bloom e Odisseu, Molly Bloom e Penélope, Stephen Dedalus e Telêmaco. Entretanto, ainda que Stephen seja o "filho espiritual" de Leopold, os Bloom têm um herdeiro literal: sua filha Milly Bloom. Como Telêmaco, Milly é o espelho da família, tem preferência clara pelo pai e entra em conflito com a mãe quando amadurece. Ambos são filhos únicos que carregam a expectativa dos pais, e quando saem de casa às pressas para um mundo que lhes dará mais experiência, continuam influenciando um lar desequilibrado. Assim, busco no presente ensaio relacionar o arco de amadurecimento de Telêmaco, um dos tripés narrativos da Odisseia, às referências feitas ao longo de Ulysses à maturidade de Milly, elencando como esses dois movimentos influenciam as ações dos demais personagens e o desenvolvimento do enredo.
\end{abstract}

Palavras-chave: Ulysses. Odisseia. James Joyce. Telêmaco. Milly Bloom.

\author{
O, Milly Bloom, you are my darling. \\ You are my looking glass from night to morning. \\ I'd rather have you without a farthing \\ Than Katey Keogh with her ass and garden.
}

(JOYCE, 1986, p. 51)

Um dos leitmotive mais facilmente identificados em Ulysses é a metempsicose - a transmigração de almas, a recorrência de vidas, a repetição (com diferenças). O próprio título aponta a migração da Odisseia para a modernidade, Leopold e Molly discutem o significado da palavra tão logo aparecem juntos em cena, e ele passa o dia retornando mentalmente a essa conversa e às implicações de diferentes tipos de "reencarnação". Mesmo Stephen, ceticamente, joga com o conceito em suas reflexões casmurras. E, se Ulysses é a Odisseia transmigrada, Gilbert (1955) e seus sucessores apontam um claro elenco principal em que Leopold Bloom é o Odisseu moderno, Molly Bloom é Penélope ilhada em sua cama e Stephen Dedalus é o jovem Telêmaco em busca de um pai. Como constata Wikes (1968, p. 309), desta perspectiva, "O enredo de Homero em Ulysses de modo geral é reduzido ao

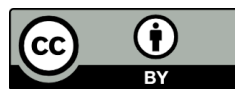

Esta obra está licenciada sob uma Creative Commons - Atribuição 4.0

\footnotetext{
* Mestre em Estudos Literários pela Universidade Federal do Paraná, UFPR (2013). Licenciada em Letras pela UNICAMP (2005). E-mail: porescrito@gmail.com.
} 
esboço mais simples: homem em busca de filho encontra filho em busca de pai; eles retornam para a esposa/mãe em casa, onde o pai vence os pretendentes dela"1.

Entretanto, neste texto tão intricadamente complexo, cheio de camadas cuidadosamente planejadas por Joyce e referências que se entremeiam e complementam, a transmigração tem várias fontes. Não há um esboço simples e ninguém cumpre um único papel. Como Gilbert (1955, p. 41) destaca, "Conforme o ciclo da história gira, a luz da fama pode tocar agora uma, agora outra faceta do todo ${ }^{2}$, , e essas facetas são muitas. Já em sua primeira cena, por exemplo, Molly não é a Penélope que aguarda o esposo, e sim Calipso, a ninfa que atrasa a partida do herói. (Calipso oferecia a Odisseu manjares deleitosos e seu corpo e mente literalmente divinos; Molly, na cama ainda quente do seu corpo, discute com o marido literatura barata e toma chá.)

O "paralelo homérico" ao qual somos convidados desde o título do romance, portanto, não é uma via única sinalizada claramente por personagens meramente duplicados, e sim uma gama de caminhos que se cruzam e seguem em muitas direções. No presente ensaio, traço um desses caminhos: me atenho à tradicional abordagem comparatista que mapeia Ulysses com base na Odisseia, mas sigo neste mapa o rastro de Milly Bloom.

Busco aqui apontar que o papel de Telêmaco, herdeiro frágil e deslocado de um reino sem rei, não é desempenhado apenas por Stephen, filho "espiritual” de Leopold, mas também por Milly, a filha "real" dos Bloom. Ainda que as trajetórias do velho Bloom e do jovem Dedalus reflitam nitidamente a busca de uma conexão como a de Odisseu e seu filho, Milly também faz parte do mosaico, retomando vários aspectos do príncipe de Ítaca. Como Telêmaco, Milly é o espelho da família, tem preferência clara pelo pai e entra em conflito com a mãe quando amadurece. Ambos são filhos únicos que carregam a expectativa dos pais, e quando saem de casa às pressas para um mundo que lhes dará mais experiência, continuam influenciando um lar desequilibrado. Telêmaco acaba por retornar a Ítaca bem a tempo de reencontrar o pai, participando de reunião familiar da qual já havia quase desistido; Milly permanece em Mullingar, mas sua sombra ronda os cômodos do número 7 da Eccles Street até as últimas páginas de Ulysses, e talvez ajude uma possível reconciliação entre Molly e Leopold.

\section{Vamos por partes.}

\footnotetext{
${ }^{1}$ Todos os textos consultados originalmente em inglês têm tradução minha. No original: "Homer's plot in Ulysses as a whole is reduced to its barest outline: man in search of son finds son in search of father; they return to wife/mother at home where father defeats her suitors."

2 "As the cycle of history turns, the light of fame may touch now one, now another, facet of the whole."
} 
Millicent Bloom aparece em muitos momentos do 16 de junho de 1904, mas não está lá em pessoa. Não a encontramos em Dublin nem a ouvimos falar ou pensar. Sua presença está apenas na mente de outros personagens, filtrada pelos olhares deles. O único momento em que temos acesso direto à voz de Milly é por meio da carta que ela envia ao pai - mas até que ponto essa garota de 15 anos, morando e trabalhando em outra cidade, ainda é a Milly melosa do queridíssimo pápi? Talvez graças a essa presença fantasmagórica, a filha dos Bloom não parece ser um dos personagens mais favorecidos na fortuna crítica joyceana. Como Eggers aponta em 1975, e Forbes reforça 30 anos depois, "os críticos que chegam a notar Milly a consideram ou uma Molly reciclada ou um substituto inadequado para Rudy" (EGGERS, 1975, p. 387). Entretanto, ela é um dos grandes estopins da narrativa, e sua ausência tem enormes consequências. Molly aponta que a presença de Milly em casa impediria seu caso com Boylan, eliminando assim uma das principais ações do enredo, ao redor do qual gira a mente de Bloom (e da própria Molly, obviamente) o dia todo:

[...] ainda mais agora com a Milly fora de casa que ideia dele mandar a menina pra lá pra aprender a tirar retrato por causa do vô dele em vez de mandar pra academia do Skerry onde ela ia ter que aprender não que nem eu sempre a primeira da turma só que ele ia fazer uma coisa dessa de qualquer jeito por causa de mim e do Boylan foi por isso que ele fez eu tenho certeza como ele planeja e trama tudo eu não podia nem me virar com ela por aqui ultimamente só trancando a porta antes me dava arrepio entrando sem bater antes [...] (JOYCE, 2012, p. 1080)

Para observar o caminho que Telêmaco e Milly percorrem juntos, vamos começar por uma breve análise do épico homérico. Na Odisseia, é possível delinear um enredo tripartido envolvendo o núcleo familiar formado por Odisseu, Telêmaco e Penélope. Desenvolvem-se, entrelaçadas, três tramas: 1) o retorno de Odisseu a Ítaca; 2) o amadurecimento de Telêmaco; 3) a (in)decisão de Penélope por um novo casamento. Para que o nostos de Odisseu seja bem-sucedido e o herói retome seu reino, ele depende não apenas de sua engenhosidade, mas também da esposa e do filho. Ela deve repelir qualquer usurpador do trono; ele não pode ser maduro o suficiente para clamar o trono para si. Os conflitos entre Telêmaco e a mãe ocorrem porque ambos já protelaram sua entrada na vida adulta por tempo demais. Sua necessidade de amadurecer, por meio da busca pelo pai, o leva para fora de casa.

Podemos facilmente traçar paralelos para essas três tramas em Ulysses: 1) o nostos de Odisseu é o protelado retorno de Bloom para casa; 2) o amadurecimento de Telêmaco se duplica em Stephen e Milly; 3) a indecisão de Penélope se reflete na consumação do caso entre Molly e Boylan, que não a impede de reconhecer Bloom como superior, de certo modo,

\footnotetext{
3 "Critics who do notice Milly consider her either as a Molly recycled or as no substitute for Rudy."
} 
a ele e aos outros homens ao seu redor.

Outro paralelo interessantíssimo é o fato de Telêmaco e Milly virem de uma linhagem de unigênitos, tendo essa característica destacada textualmente - Telêmaco é filho único de Odisseu, que é filho único de Laerte, que também é filho único (“Zeus / uniprocriou nossa família de unigênitos: / Arquésio teve um filho só, Laerte, pai / de um único, Odisseu, que mais do que um não teve / em seu palácio, sem gozar de um tal convívio", HOMERO, 2011, p. 483, 16.117); Milly é a única filha viva do casal Bloom (que perdeu Rudy com apenas 11 dias de vida), e tanto Leopold quanto Molly também são filhos únicos ("Engraçado ela filha única, eu filho único. Assim retorna. Você pensa que está fugindo e dá de cara com você mesmo", JOYCE, 2012, p. 594). Isso intensifica uma noção de isolamento e singularidade das famílias e desses herdeiros. A Guerra de Troia separou Odisseu e Penélope e impediu que Telêmaco tivesse irmãos; a morte de Rudy ainda bebê deixou uma presença fantasma separando o casal Bloom:

[...] o completo conluio carnal, com ejaculação de sêmen dentro do órgão natural da mulher, havia ocorrido pela última vez cinco semanas antes, i.e., 27 de novembro de 1893, do nascimento em 29 de dezembro do segundo (e único masculino) rebento, falecido em 9 de janeiro de 1894, aos 11 dias de idade, restando um período de 10 anos, 5 meses e 18 dias durante o conluio carnal havia sido incompleto. (JOYCE, 2012, p. 1035).

Apesar dessas muitas semelhanças entre Telêmaco e Milly, também há divergências, que retomam a ideia de que a história se repete sim, mas com diferenças. Telêmaco, superprotegido por Penélope (ele é o último vestígio do marido), começa a Odisseia um jovem com mais de 20 anos que permanece imaturo. Memória viva do pai, é comparado a ele por Atena, disfarçada de Mentes: "És filho de Odisseu? Como cresceste tanto? / Direi que a testa é a mesma e que possuis o olhar / tão belo quanto o dele [...]” (HOMERO, 2011, p. 25, 1.206-208). A semelhança, entretanto, é apenas física. O filho não parece ter herdado a engenhosidade, coragem ou iniciativa típicas do pai. Ao menos, ainda não. Assim, sua resposta é incerta: "minha mãe me garante que sou filho dele, / mas ignoro: ninguém conhece a própria / ascendência" (HOMERO, 2011, p. 25, 1.115-217). No background do épico do pai, se desenrola o minibildungsroman de Telêmaco. Por meio das mudanças de suas ações e de sua voz, vamos testemunhar o surgimento de uma confiança inesperada.

Milly, em contrapartida, tem um caráter muito estável. Entretanto, como já mencionado, ela está ausente da Dublin que Ulysses mapeia, e temos de nos contentar em delinear sua personalidade e suas ações com base na carta de agradecimento que ela envia ao pai, a cujo texto integral temos acesso, e nas memórias de quem a conhece, como detalha 
Benstock (1982, p. 418):

O mais perto de uma aparição em cena de Milly Bloom em Ulysses é por meio dessa carta; e ainda assim nós não conseguimos apontar precisamente como a carta reflete a personalidade, as convenções de discurso ou a presença dela. [...] Nosso 'conhecimento' de Milly Bloom tem outras fontes em Ulysses além da carta. Pelo menos dois personagens no romance - Molly e Leopold - a conhecem bem, pensam nela com frequência, lembram-se das ações, falas e características físicas dela - e tudo isso reforça a impressão que recebemos por meio da carta ${ }^{4}$.

Assim, somos o público diante do qual Telêmaco luta para se tornar um adulto, mas estamos em segundo ou terceiro plano quando se trata da puberdade de Milly. E, apesar disso, conseguimos ter uma visão razoavelmente clara sobre ela, pois a carta, Leopold, Molly e até mesmo Bannon apresentam uma imagem estável: Milly é ativa, enérgica, independente. Até mesmo nas lembranças de sua infância, Leopold a vê em movimento constante, um feixe de luz: "Velozquente luz do sol veio corrente da Berkeley Road, vivaz, com sandálias exíguas, pela trilha que se abrilhantava" (JOYCE, 2012, p. 172); e, acima de tudo, precoce: "Aquela noite que a Milly trouxe pra sala. Ó o que eu achei no chapéu do professor Goodwin! Todo mundo riu. Já era o sexo aparecendo. Figurinha assanhada que ela era" (JOYCE, 2012, p. 174). É assim também "garota da foto" de Bannon: "uma novilha espevitada, crescida para sua idade e de canela grossa" (JOYCE, 2012, p. 621).

Telêmaco parece algo incompleto, um reflexo falho dos pais, mas Milly é uma mistura de Leopold e Molly, e, do auge dos seus 15 anos, já é vista como uma mulher. O pai diz: "Molly. Milly. A mesma coisa diluída. [...] Sim, sim: mulher também. Vida, vida" (JOYCE, 2012, p. 209), mas também canta “Ó Milly Bloom, meu coração, / És meu espelho do começo ao fim" (JOYCE, 2012, p. 174) e se reconhece nela em pequenos detalhes do dia a dia (e no nariz). A mãe vê ainda mais claramente características de ambos na garota, comparando-se constantemente com a filha e identificando nela as artes típicas de Leopold:

[...] eu percebi que ele andava falando com ela o tempo todo ultimamente na mesa explicando as coisas no jornal e ela fingindo que entendia malandrinha claro isso vem do lado dele [...] a sua blusa está aberta demais ela me diz o roto rindo do esfarrapado e eu tive que dizer pra ela não levantar as pernas daquele jeito exibidinha na soleira da janela da frente de todo mundo que passava eles todos olham pra ela que nem eu quando eu tinha a idade dela claro que qualquer trapinho fica bem em você nessa época aí cheia de nãometoques também [...] ela fica inquieta sabendo que é bonita com aquela boca tão vermelha pena que não vai ficar assim eu era também [...] (JOYCE, 2012, p. 1081-1083)

\footnotetext{
4 "The closest to an on-scene appearance of Milly Bloom in Ulysses is through this letter; and yet we cannot say precisely how the letter reflects her personality, her speech conventions, or her presence. [...] Our "knowledge" of Milly Bloom has other sources in Ulysses outside de letter. At least two characters in the novel - Molly and Leopold - know her well, think of her often, recall her actions, her speech, her physical characteristics - all of which reinforce the impression of her that we receive through the letter."
} 
Leopold e Molly, cada um à sua maneira, se orgulham de Milly. Ele reflete repetidamente sobre sua beleza (os cabelos e as pernas pipocam aqui e acolá) e rememora satisfeito o interesse dela em suas explicações científicas: "ela expressava o imediato desejo de possuir sem gradual aquisição uma fração de sua ciência, a metade, um quarto, um milésimo" (JOYCE, 2012, p. 981). Ele também ostenta para os conhecidos o trabalho que a filha conseguiu: "Supimpa, o senhor Bloom disse alegre, a Milly arrumou um emprego lá em Mullingar, sabia?" (JOYCE, 2012, p. 298). Molly, por sua vez, a vê como mais um sinal de sua superioridade diante de seus pares: “[...] elas que arranjem um marido primeiro que valha a pena a gente olhar e uma filha que nem a minha [...]" (JOYCE, 2012, p. 1075), e reconhece sua inteligência ("a primeira da turma").

Telêmaco demora um pouco mais para ser motivo de orgulho. Conforme apontado, ele começa a Odisseia encolhido, calado, inerte. Incapaz de defender seu oikos dos pretendentes da mãe, tudo que faz é ficar amuado em um canto do palácio e desejar o retorno do pai. Quando Atena decide intervir, disfarçada como Mentor, o garoto é assim descrito:

\footnotetext{
Telêmaco deiforme a vê primeiro, ao lado dos pretendentes, coração ensombrecido, visão do pai gravada no íntimo, se acaso, de volta a seu palácio, ele enxotasse os procos, senhor dos próprios bens, mantenedor da fama. (HOMERO, 2011, p. 19, 1.113-117)
}

O desabrochar dele ocorre após ser incitado por Atena, que vê a ausência do pai como um retardante de seu amadurecimento. Uma breve conversa com a deusa é suficiente para despertar coragem, altivez e iniciativa súbitas e inesperadas. Seu primeiro ato é retrucar uma solicitação de Penélope (que o aedo parasse de cantar sobre Odisseu), o que a surpreende sobremaneira:



$\mathrm{Na}$ sequência, ele discute com os pretendentes, o que também os impressiona enormemente: "assim falou, e, remordendo os lábios, todos / ficam embasbacados com a fala audaz" (HOMERO, 2011, p. 35, 1.382-383). É só depois dessa rebelião na própria casa que Telêmaco planeja sua partida para Esparta, em busca de notícias do pai, em busca do mundo. 
Em sua rebeldia juvenil, Milly também enfrenta a mãe, mas com resultados ligeiramente diferentes. Afinal, Molly não é a face mais tranquila da prudente Penélope, e rememora: “[...] eu dei-lhe 2 bofetadas das boas nas orelhas pra ela ver toma essa por responder desse jeito e essa pelo desaforo ela me irritou de uma tal maneira claro me contradizendo [...]" (JOYCE, 2012, p. 1083).

A partida de Telêmaco em busca de notícias do pai (e, indiretamente, de experiências que possam levá-lo a se tornar um adulto), sem o conhecimento dos pretendentes nem o consentimento da mãe, impressiona seus inimigos, que planejam assassiná-lo antes que ele amadureça o suficiente para ser uma ameaça ainda maior:

O feito que Telêmaco cumpriu viajando
está longe de ser menosprezável. Quem
esperaria? O rapazote parte sem
temor, coloca a nau no mar, escolhe sócios:
onde mais tarde irá parar? Possa o Cronida
anular seu vigor, em fase pré-adulta! [...]
(HOMERO, 2011, p. 133, 4.664-670)

A ameaça da "fase pré-adulta" de Milly também tem a ver com vigor, mas, dessa vez, sexual. Após ler a carta em que ela menciona "um estudante que vem aqui às vezes chamado Bannon" (JOYCE, 2012, 178), Leopold mergulha em reflexões que vão do nascimento dela até a possível (e próxima) perda da virgindade, sem saber ao certo se ela está ou não pronta para isso:

\footnotetext{
Apressada. Piano lá embaixo. Saindo da concha. A briga com ela no café XL por causa da pulseira. Não comia mais o bolo nem falava nem olhava. Pimentinha. [...] Ora: ela sabe se cuidar. Mas e se não? Não, não aconteceu nada. Claro que podia. Espere enfim até acontecer. Figurinha difícil. As pernas esbeltas dela subindo a escada correndo. Destino. Amadurecendo agora. Fútil: muito. (JOYCE, 2012, p. 179)
}

Ainda que Leopold seja acometido por repetidas visões da infância da filha, a imagem que se sobressai é essa: sim, sim, mulher também. Em breve "roubada" por outro homem, comparada com a gata que vai e vem quando quer: "similarmente, pois movida por um propósito secreto a busca de um novo macho (estudante de Mullingar) ou de uma erva medicinal (valeriana). Diferentemente, por causa dos diferentes retornos possíveis aos habitantes ou à habitação" (JOYCE, 2012, p. 979). As reclamações de Molly também são de teor sexual, mas vistas de outro ângulo: Milly está vivendo o que ela já viveu, e tudo lhe parece um déjà vu. Se o medo de Leopold é perder $a$ filha, o de Molly é perder para a filha, e as ações dela parecem imitações deselegantes: 
[...] ela está bendisposta a flertar também com os dois filhos do Tom Devans me imitando assoviando [...] foi até bom ele mandar ela lá pra onde ela foi ela estava começando a sair do limite querendo ir no rinque de patinação e baforejando os cigarros deles pelo nariz [...] (JOYCE, 2012, p. 1081)

Apesar disso, e dos bofetões, e da maquiagem roubada, sabemos que não partiu de Molly a ideia de enviar Milly para longe. Como no caso de Telêmaco, o afastamento da mãe é fruto da influência paterna. Enquanto ele parte em busca do pai, ela parte a mando do pai. A melancolia de Molly transparece na lembrança da despedida das duas, "[...] e ela nem quis que eu desse um beijo nela no terminal na despedida [...]" (JOYCE, 2012, p. 1082), e espelha, em grau muito mais moderado, o desespero de Penélope quando descobre a partida do filho: “[...] O coração e os joelhos da rainha / baqueiam. Sílaba, uma só, não fala, as lágrimas / decaem do olhar, e, quase à tona, a voz aborda. / A fala se lhe volta, após o hiato: 'Arauto, / por que meu filho foi-se? [...]"' (HOMERO, 2011, p. 135, 4.704-707). Também há um quê de tristeza por parte de Molly quando chegam as correspondências da filha e ela nota a diferença feita entre ela e Leopold: “[...] e o postal da Milly hoje de manhã está vendo ela escreveu uma carta para ele de quem foi a última carta que eu recebi [...]" (JOYCE, 2012, p. 1068). Ciúme? Inveja? Seja o que for, é clara para Molly a preferência da filha pelo pai.

O contraste entre a relação tão próxima entre Leopold e Milly e o fato de ele ter sido a pessoa a tirá-la de casa é peculiar. Ao mesmo tempo em que ele sente falta da filha e planeja visitá-la (sans Molly), prefere mantê-la distante:

Melhor lá onde ele está: longe. Manter ocupada. Precisava de um cachorro pra passar o tempo. Podia dar uma passada lá. Feriado nacional em agosto, só dois e seis ida e volta. Mas faltam seis semanas. Podia conseguir uma credencial de imprensa. Ou com o M'Coy. (JOYCE, 2012, p. 180)

Molly, como vimos, acha que o marido queria abrir caminho para ela e seu amante. Mas o que Leopold talvez busque seja uma conexão maior com a esposa, afinal, "o completo conluio mental entre ele e a ouvinte não havia ocorrido desde a consumação da puberdade, indicada por hemorragia catamênica, do rebento feminino" (JOYCE, 2012, p. 1035). Nos resta especular.

A viagem de Milly para o mundo não tem prazo de volta, mas a de Telêmaco sim. Após suas aventuras em busca de notícias do pai, o jovem retorna a Ítaca ainda mais impetuoso, pronto para lutar contra os inimigos. E é lá que encontra Odisseu, também retornado de suas aventuras. Pai e filho juntos planejam vingar-se dos pretendentes. Entretanto, antes do conflito final, surge um último teste. Penélope propõe a prova do arco, em que aqueles que desejam sua mão e, consequentemente, o poder em Ítaca, devem alcançar 
um feito só conseguido por Odisseu: manusear o arco gigantesco do herói e transpassar doze machados com uma única flecha. Supreendentemente, o primeiro a se oferecer é Telêmaco.

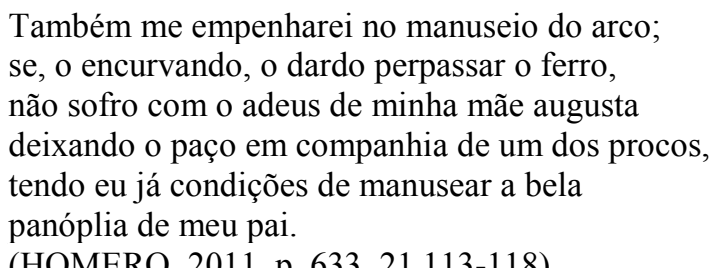

Ainda que não tenha a intenção de realmente usurpar o poder em Ítaca, uma vez que já recebera o pai, aos prantos, Telêmaco aproveita a oportunidade para mostrar sua maturidade. Afinal, já se sente capaz de se equiparar a ele. Mas ele falha. E essa falha mostra que, apesar de ter passado por muitas mudanças ao longo do épico, ele ainda é uma versão "diluída" do pai. Pai e filho matam juntos os pretendentes, sim, mas, ao enfrentar o restante da cidade, Odisseu ainda não confia na maturidade do garoto, e o exorta:

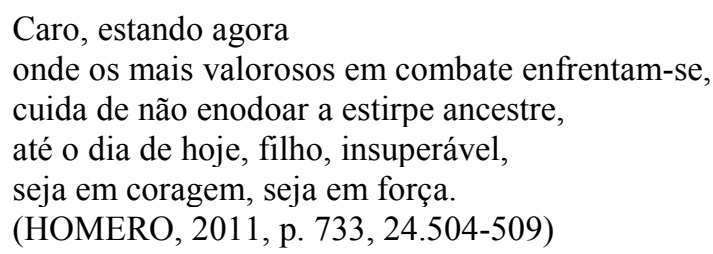

Telêmaco garante ao pai que demonstrará coragem, mas não o vemos pô-la em prova: Atena dispersa a multidão. E é essa nossa última imagem de pai e filho (e avô, incrivelmente). Unidos, mas não equiparados.

Assim, enquanto a última menção a Telêmaco o mostra no seio da família, quaseadulto, Milly, como vimos, talvez não volte para casa, mas (ou pois?) já é tida como adulta. A "falha" de Telêmaco permite que Odisseu retome o poder. A "vitória" de Milly a afasta dos pais, mas talvez permita que Leopold retome também o seu lugar. Se a partida da filha, como imagina Molly, foi planejada por Leopold para que ela tivesse um caso com Boylan, e mesmo as proezas sexuais dele não foram suficientes para desbancar seu marido ("o Poldy pelo menos apesar de tudo", JOYCE, 2012, p. 1047), talvez ainda haja espaço para reconciliação. Se a morte de Rudy causou uma ruptura familiar intensa, é possível que a partida de Milly abra espaço para outras possibilidades. Além disso, agora os Bloom têm um quarto disponível, já oferecido para outro Telêmaco...

Encerramos aqui nosso percurso com os dois herdeiros à beira da vida adulta: Telêmaco e Milly se afastam de seus lares em uma jornada à maturidade, mas não conseguem se desvincular de suas famílias. Os pais continuam refletidos nos filhos; os filhos influenciam 
sem cessar as ações dos pais. No épico homérico e no romance de Joyce, até mesmo a ausência desses jovens desempenha papel crítico no andamento da trama, indicando sua relevância na narrativa e levando a desfechos repletos de possibilidade.

\section{Agradecimentos}

Prof. Dr. Caetano Waldrigues Galindo (UFPR)

\section{Referências}

BENSTOCK, Shari. The printed letters in Ulysses. James Joyce Quarterly, Tulsa, v. 19, n. 4, p. 415-427, summer 1982.

EGGERS, Tilly. Darling Milly Bloom. James Joyce Quarterly, Tulsa, v. 12, n. 4, p. 386-395, summer 1975.

FORBES, Shannon. Joyce's 'saucebox': Milly Bloom's Portrait in Ulysses. Irish Studies Review, Abingdon, v. 14, n. 1, p. 39, 2006.

GILBERT, Stuart. James Joyce’s Ulysses: a study. New York: Random House, 1955.

HOMERO. Odisseia. Tradução, posfácio e notas: Trajano Vieira. São Paulo: 34, 2011.

JOYCE, James. Ulysses. New York: Random House, 1986.

Ulysses. Tradução: Caetano W. Galindo. São Paulo: Penguin Classics Companhia das Letras, 2012.

WYKES, David. The Odyssey in Ulysses. Texas Studies in Literature and Language, Texas, v. 10 , n. 2, p. 301-316, summer 1968 .

\section{History repeating itself with a difference: Telemachus' and Milly Bloom's coming-of-age arcs}

Abstract: Among the many references and multiple parallels between James Joyce's Ulysses and Homer's Odyssey, the mirroring between Leopold Bloom and Odysseus, Molly Bloom and Penelope, Stephen Dedalus and Telemachus stands out. However, although Stephen is the "spiritual son" of Leopold, the Blooms have a more literal heir: their daughter Milly Bloom. Just like Telemachus, Milly is the mirror of the family, has a clear preference for her father and clashes with her mother as she get older. Both are only children who carry the expectation of their parents, and when they hurriedly leave their homes for a world that will give them more experience, they continue to influence an unbalanced home. Therefore, in this paper, my aim is to point out how Telemachus coming-of-age, one of the three narrative strands of the Odyssey, relates to the references made throughout Ulysses to Milly's maturity, indicating how these two movements affect the actions of other characters and the development of the plot. 
Keywords: Ulysses. Odyssey. James Joyce. Telemachus. Milly Bloom.

Recebido em: 08/04/2017

Aceito em: 24/10/2017

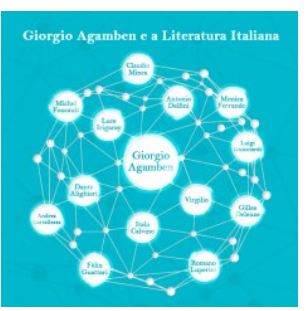

